Research Article

\title{
A Study of Investigation on Increased Stiffness of Diaphragm in High Rise Building under Seismic Load
}

\author{
Mohd Mujeebuddin Ahmed $^{\dot{A}^{*}}$, N. Venkat Rao ${ }^{\dot{A}}$, Mohd Abdul Baseer $^{\dot{A}}$, M. Rajasekhar $^{\dot{A}}$ \\ ${ }^{\dot{A}}$ Department of Civil Engineering, Vardhaman College of Engineering, Shamshabad, Hyderabad, Andhra Pradesh, India.
}

Accepted 10 January 2014, Available online 01 February 2014, Special Issue-2, (February 2014)

\begin{abstract}
The galloping growth of population, rapid industrialization, and increased urbanization encouraged the migration of population to urban areas. The accumulation of population led to the formation of slums this enhanced the demand of infrastructure creation. Building structures become larger and taller to satisfy the social and economical needs of growing urban population. Under these circumstances a need was felt to create more number of accommodations in limited space, the result of the effort was creation of high rise structures. The advanced and sophisticated technology has been emerged to create avenues with economy and durability. Various works have been carried out to study the behavior of these structures and increase the lateral stiffness. The advances in three-dimensional structural analysis and computing resources have allowed the efficient and safe design of increasingly taller structures. Tall buildings are being increasingly designed with structural system comprising of flat slab or flat plate system and shear wall with or without perimeter beams. The behavior of this system under lateral loads is dependent on numerous parameters such as the height of the building, size of the floor plate size and location of the shear wall, flat slab spans. The flexural stiffness of floors may have some influence on the lateral response of the structure. Under lateral loading floor and roof systems in reinforced concrete buildings act as diaphragms to transfer lateral loads to the vertical lateral force resisting system. If the flexural stiffness of slabs is totally ignored the lateral stiffness of the structure may be underestimated. The analysis has been carried out to study the effect of increased stiffness of diaphragm in Lateral load resisting Performance of an 30 storey building with Perimeter Frames, Flat Slab, Shear wall and increased stiffness of diaphragm.
\end{abstract}

Keywords: Diaphragm stiffness, Shear wall, Flexibility, Joint load, Nodal load, Centre of mass displacement, Shear deformation.

\section{Introduction}

\subsection{Lateral Forces}

Lateral forces due to seismic loading must be considered in design of structures along with gravity forces. The magnitude of the lateral force on a structure is not only dependent on the acceleration of the ground but it will also depend on the type of the structure. The term lateral loads describes the effect of wind and seismic forces, even though in the recent past it included any horizontal applied forces, this terminology seeks to differentiate lateral loads from the downward acting gravity loads, even though in reality the seismic and wind forces can act in both horizontal and vertical directions. Indeed, modern building codes require that wind be applied perpendicular to roof surfaces-nearly upward for shallow roofs-and that a percentage of earthquake loading be applied vertically (Taranath.B.S. (2001)).The two types of lateral loads considerably vary and at times the requirements may be conflicting. For e.g. one strategy to reduce vibration of tall structures due to wind load is to increase its mass whereas

*Corresponding author: Mohd Mujeebuddin Ahmed

DOI: http://dx.doi.org/10.14741/ijcet/spl.2.2014.61 increase in mass usually causes increase in the lateral load due to earthquake. It is therefore very important to understand the relative importance of wind and earthquake on a structure located at a particular site.

\subsection{Wind Loads}

The effects of wind on structures are still not perfectly understood and our knowledge in this area is constantly improving with the periodic revisions of the applicable wind code provisions. High winds can cause four types of structural damages which are stated as Collapse, partial collapse, over damage and sliding Often partial damage occurs most frequently.( P. Jayachandran, May 2009). Wind forces are applied perpendicular to all roofs and walls and both internal and external wind pressures are considered. Wind is not constant with height or with time, is not uniform over the side of the structure and does not always cause positive pressure. Both the wind pressure and the wind suction must be taken into account during the structural analysis. Pressure coefficients used in the practice have usually been obtained experimentally by testing models of different types of structures in wind 
tunnels. When wind interacts with a structure, both positive and negative pressures occur simultaneously.

\subsection{Earthquake Load}

Seismic motions consist of horizontal and vertical ground motions, with the vertical motion usually having a much smaller magnitude. The factor of safety provided against gravity loads usually can accommodate additional forces due to vertical acceleration due to earthquakes. So, the horizontal motion of the ground causes the most significant effect on the structure by shaking the foundation back and forth. However in practice all structures are flexible to some degree but a very flexible structure will be subjected to a much longer force under repetitive ground motion. This shows the magnitude of the lateral force on a structure is not only dependent on the acceleration of the ground but it will also depend on the type of structure (F=Ma). ( $\mathrm{K}$. Galal and H. El-Sokkary 2008). The earthquake load is estimated by response spectrum method in the project and is as specified by the provisions in IS 1893.In the earthquake resistant design focus is on the ductility and energy absorption by the material used (steel) for construction. It was shown repeatedly that no static analysis can assure a good dissipation of energy and favourable distribution of damage in irregular structures and in general the more slender a structure, the worse the overturning effect of an earthquake.

\section{Distributions of Lateral Forces}

\subsection{Diaphragms}

Horizontal distribution of lateral forces to shear walls is achieved by the floor and roof systems acting as diaphragms. To qualify as a diaphragm, a floor and roof system must be able to transmit the lateral forces to the shear walls without exceeding a deflection which would cause distress to any vertical element. Diaphragms may be considered as analogous to horizontal (or inclined, in the case of some roofs) plate girders. The roof or floor slab constitutes the web; the joists, beams and girders function as stiffeners; and the walls or bond beams act as flanges. The stiffness of a horizontal diaphragm affects the distribution of the lateral forces into the shear walls. No diaphragm is infinitely rigid or flexible. However, for the purpose of analysis, diaphragms may be classified into three groups: rigid, semi rigid or semi flexible, and flexible.

\subsection{Diaphragm Deflection}

As previously indicated, deflection is another factor that must be considered in designing a horizontal diaphragm. As shown in Fig.1, diaphragm deflection should be limited to prevent excessive stresses in the walls which are perpendicular to the shear walls. The following formula has been suggested by the Structural Engineers Association of Southern California for allowable deflection of horizontal diaphragms in buildings having masonry or concrete walls:

$\Delta=\frac{h^{2} \mathrm{f}}{0.01 \mathrm{Et}}$

Where: $\Delta=$ allowable deflection between adjacent supports of wall, in inches

$\mathrm{h}=$ height of wall between adjacent horizontal supports, in feet

$\mathrm{t}=$ thickness of wall, in inches

$\mathrm{f}=$ allowable flexural compressive stress of wall material, in pounds per square inch

$\mathrm{E}=$ modulus of elasticity of wall material, in pounds per square inch.

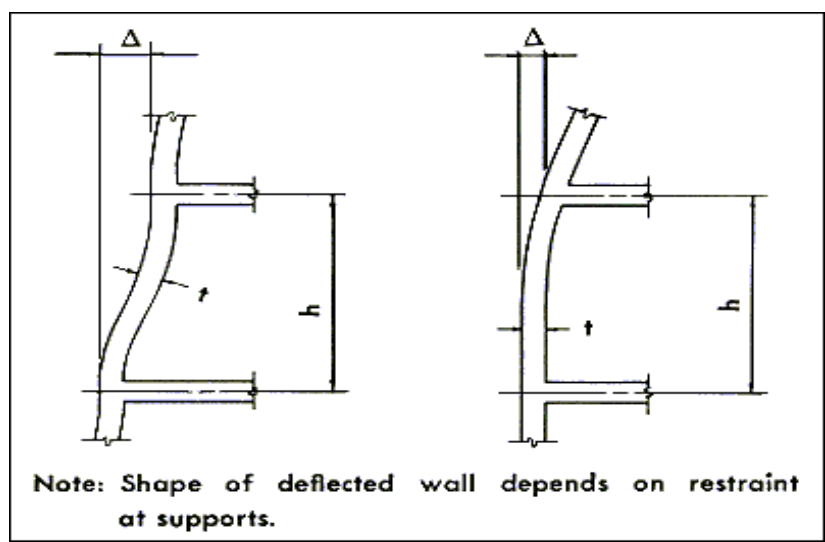

Fig.1. Diaphragm Deflection Limitation

The application of these limits on deflection must be used with engineering judgment. For example, continuity at floor level is assumed, which in many cases is not present due to through-wall flashing. In this situation the deflection may be based on the allowable compressive stress in the masonry, assuming a reduced cross section of wall. The effect of reinforcement which may be present in a reinforced brick masonry wall or as a tie to the floor system in a non-reinforced or partially reinforced masonry wall is not considered. It should also be pointed out that the limit on deflection is actually a limit on differential deflection between two successive floor or diaphragm levels. Maximum span-to-width or depth ratios for diaphragms are usually used to indirectly control diaphragm deflection. Normally, if the diaphragm is designed with the proper ratio, the diaphragm deflection will not be critical. (Laporan Akhir, November 2006).

\section{Shear Wall-Frame Interaction}

The interaction of frame and shear walls has been understood for quite some time ; the classical mode of the interaction between a prismatic shear wall and moment frame is shown in fig. 2; the frame basically deflects in so called shear mode while the shear wall predominantly responds by bending as a cantilever. Compatibility of horizontal deflection produces interaction between the two. The linear sway of the moment frame, when combined with the parabolic sway the shear wall results in an enhanced stiffness because the wall is restrained by the 
frame at upper levels while at the lower levels shear walls is restrained by the frame. Considering the separate horizontal stiffness's at the top of typical 10-story elevator core and a typical rigid frame of the same height, the core might be 10 or more times as stiff as the frame. If the same frame and core were extended to a height of 20 stories the core would be approximately three times as stiff as the frame. At 50 storeys's the core would have reduced to being only half as stiff as the core. This change in relative top stiffness with the total height occurs because the top flexibility of the core, which behaves as flexural cantilever, is proportional to cube of the height whereas the flexibility of the frame which behaves as a shear cantilever is directly proportional to its height. Consequently height is the major factor in determining the influence of the frame on the lateral stiffness of the wallframe. The combined structural action therefore depends on the relative rigidity of the two, and their modes of deformation.(Dong- Guen Lee, et-al. 2004 ) Furthermore, the simple interaction diagram is valid only if

- The shear wall and frame have constant stiffness throughout the height or;

- If stiffness vary, the relative stiffness of the wall and frame remains unchanged throughout the height

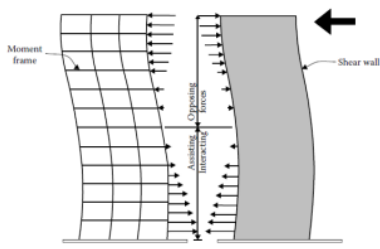

Fig.2 Shear wall frame interaction

\section{Numerical Study}

In the present study the analysis is done confirming the Indian Code of Practice. This building does not represent a particular real structure that has been built or proposed. However, the dimensions, general layout and other characteristics have been selected to be representative of a building. Studies have been made for the storey displacement, storey drift, moments etc. for given loading. For this three dimensional analysis of the given building was performed on ETABS for gravity as well as for lateral loadings.( Young S.Cho, 'et-al.' 2004).

\subsection{Building Type and Dimensions}

\section{Structure 1: Flat Slab 200mm with Drop}

It is a 30 Storey building with a height of $90 \mathrm{~m}$. The typical floor height is $3.00 \mathrm{~m}$. The base plan area of the structure is $40 \mathrm{~m} \times 30 \mathrm{~m}$ with columns spaced $8 \mathrm{~m}$ from centre to centre in $\mathrm{X}$-direction and $6 \mathrm{~m}$ centre to centre in $\mathrm{Y}$-direction in as shown in fig.3. The entire columns size up to 15 th floor is $0.8 \times 0.8 \mathrm{~m}$, and remaining floors with a size of $0.75 \times 0.75 \mathrm{~m}$. The columns have been provided at about $8.00 \mathrm{~m}$ spacing in $\mathrm{X}$-direction and $6.00 \mathrm{~m}$ spacing in $\mathrm{Y}$-direction. Perimeter Framing beam size is $0.40 \mathrm{x} 0.60 \mathrm{~m}$ connecting all periphery columns. The Flat slab thickness for all slabs is $0.200 \mathrm{~m}$ with drop panels of size $3 \times 3 \mathrm{~m}$. The thickness of drop panel is $0.150 \mathrm{~m}$. Shear wall of $4 \mathrm{~m}$ with a thickness $0.250 \mathrm{~m}$ is provided in all four corners in both directions.

\section{Structure 2: Flat Slab 250mm without Drop}

For the Structure Case:1, the flat slabs are converted into a floor plate with a thickness of $0.250 \mathrm{~m}$.

\section{Structure 3: Increased stiffness of diaphragm 300mm at regular intervals.}

For the structure Case: 2, the flat slabs are converted into a floor plate with a thickness of $0.250 \mathrm{~m}$ except multiples of 5th floor with a thickness of $0.300 \mathrm{~m}$.

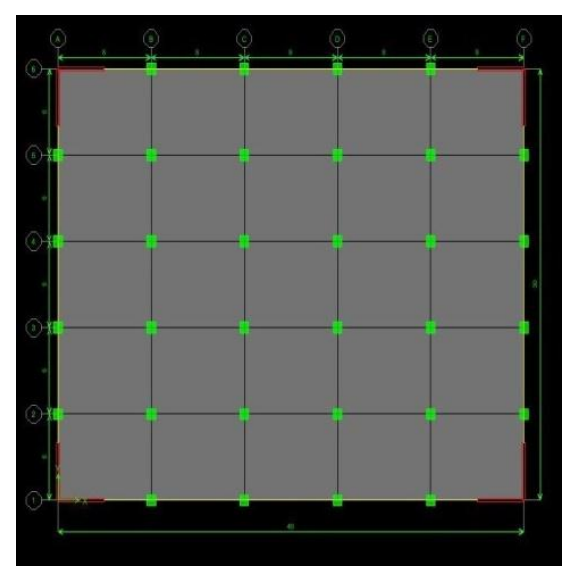

Fig.3 Base Plan of All Structures

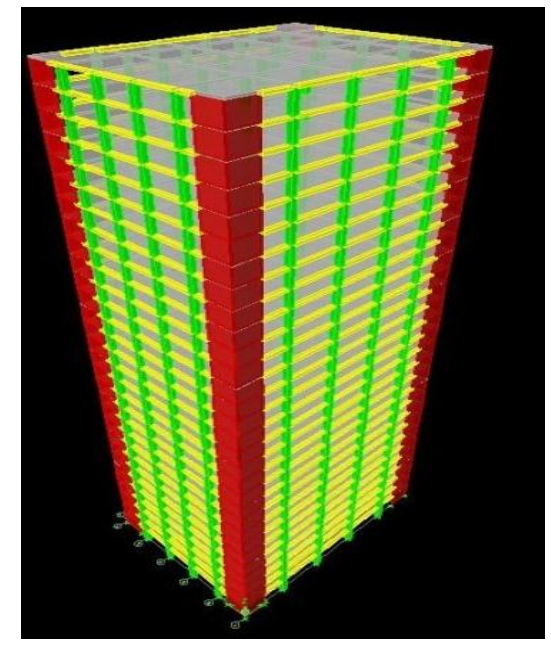

Fig.4 Elevation of All Structures

\subsection{Building Description}

- No. of storey: 30

- Grade of concrete : $\mathrm{M}_{40}$

- Storey Height: $3.0 \mathrm{~m}$ Columns: column size upto $15^{\text {th }}$ floor is $800 \mathrm{~mm} \times 800 \mathrm{~mm}$ and $16^{\text {th }}$ to $30^{\text {th }}$ floor is $750 \mathrm{~mm} \times 750 \mathrm{~mm}$ for all structures.

- Shear wall thickness: $250 \mathrm{~mm}$ for all structures. 
- Perimeter framing Beam size: $400 \mathrm{~mm}$ x $600 \mathrm{~mm}$ for all structures.

- Slab thickness: Structure1: 200mm with drop, Structure2: $250 \mathrm{~mm}$ without drop, Structure3: $250 \mathrm{~mm}$ except regular intervals of $5^{\text {th }}$ floor of $300 \mathrm{~mm}$.

\subsection{Loads on the structure}

\subsubsection{Dead Load Calculations}

The columns size up to 15 th floor $=0.80 \times 0.80 \mathrm{~m}$

16th to 30th floor $\quad=0.75 \times 0.75 \mathrm{~m}$

Perimeter Framing beam size $\quad=0.40 \times 0.60 \mathrm{~m}$

Flat slab thickness:

Structure $1=0.200 \mathrm{~m}$ with drop panels

Structure $2=0.250 \mathrm{~m}$

Structure $3=0.250 \mathrm{~m}$ except regular intervals of 5 th floor of $0.300 \mathrm{~m}$
Size of shear wall
$=4 \mathrm{~m}$

Shear wall thickness up to 30th floor $=0.250 \mathrm{~m}$

Floor Finish Loads

$$
=1.00 \mathrm{KN} / \mathrm{Sqm}
$$

\subsubsection{Live Load Calculations}

Live load for all floors

Grade of Concrete

Grade of Steel

Number of Floor

Each Floor Height

$$
\begin{aligned}
& =2.00 \mathrm{KN} / \mathrm{Sqm} \\
& =\mathrm{M} 40 \\
& =\mathrm{Fe} 500 \\
& =30 \mathrm{No} \\
& =3.00 \mathrm{~m}
\end{aligned}
$$

\subsubsection{Wind Parameters}

Life of Structure

Terrain Category

Topography

Structure Type

Basic Wind Speed $\mathrm{V}_{\mathrm{b}}$

Risk Coefficient ( $\mathrm{K}_{1}$ factor)

Topography $\left(\mathrm{K}_{3}\right.$ factor)

$$
\begin{aligned}
& =50 \text { years } \\
& =3 \\
& =\text { Flat } \\
& =\mathrm{B} \\
& =50 \mathrm{~m} / \mathrm{s} \\
& =1 \\
& =1
\end{aligned}
$$

\subsubsection{Seismic Parameters}

From IS 1893 (Part-1) - 2002

Zone Factor $(\mathrm{Z}) \quad=0.16$

(Seismic Zone 3 - Table-2 Clause 6.4.2)

Importance Factor (I) (Table-6 Clause 6.4.2) $=1.0$

Response Reduction Factor $(\mathrm{R})=5.0$

(Table 7 Clause 6.4.2)

Structural Soil (SS) =1.0 (Fig 2 Type 1 Rock or Hard soil)

Structure Type $(\mathrm{ST}) \quad(\mathrm{RC}$ Frame Building $)=1.0$

Damping Ratio $\left(\mathrm{D}_{\mathrm{mp}}\right)=0.05$

\subsection{Load Combinations}

Base Shear, storey axial Forces, Storey Torsion, .Storey Shear Force, Storey Moment,

1.1.2(DL + LL + WL X) 2.1.2(DL + LL + WL Y $)$

\subsubsection{Serviceability Load Combinations:}

CM Displacement, . Storey Drift
1. $\mathrm{DL}+0.8(\mathrm{LL}+\mathrm{EQX})($ in $\mathrm{m})$

2. $\mathrm{DL}+0.8(\mathrm{LL}+\mathrm{EQY})($ in $\mathrm{m})$

\subsection{Analysis of Results}

The Analysis is carried out for the Lateral load resisting performance of a 30 Storey building for the 3 Structure.

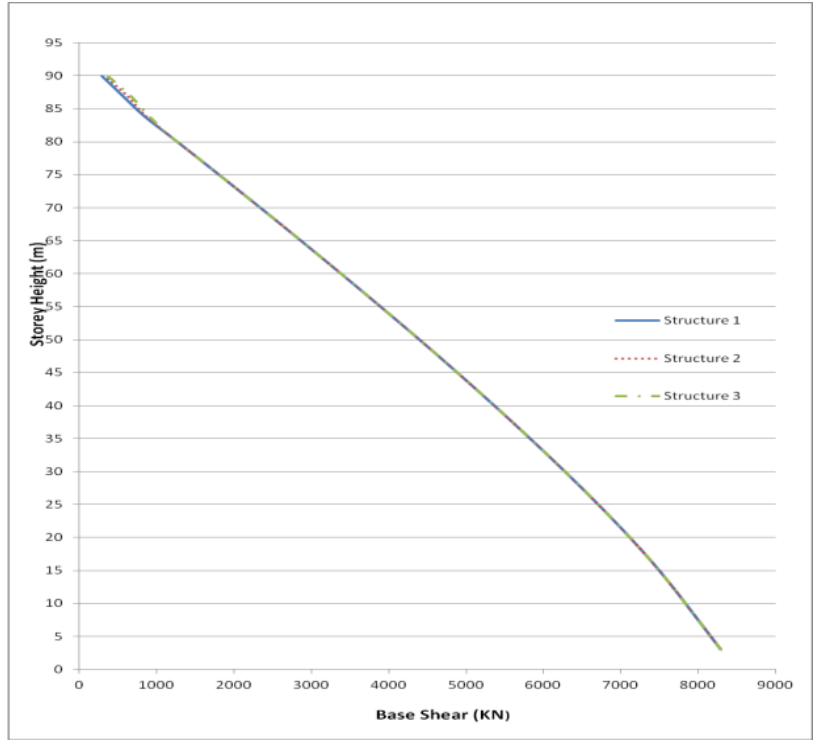

Fig.5 Storey wise distribution of base shear (in $\mathrm{kN}$ ) for all structures in X-direction

A graph is plotted taking base shear $(\mathrm{kN})$ on $\mathrm{X}$ axis and storey height $(\mathrm{m})$ on $\mathrm{Y}$ axis. From the fig 5 it is observed that all the three structures are having the same base shear value in $\mathrm{X}$-direction.

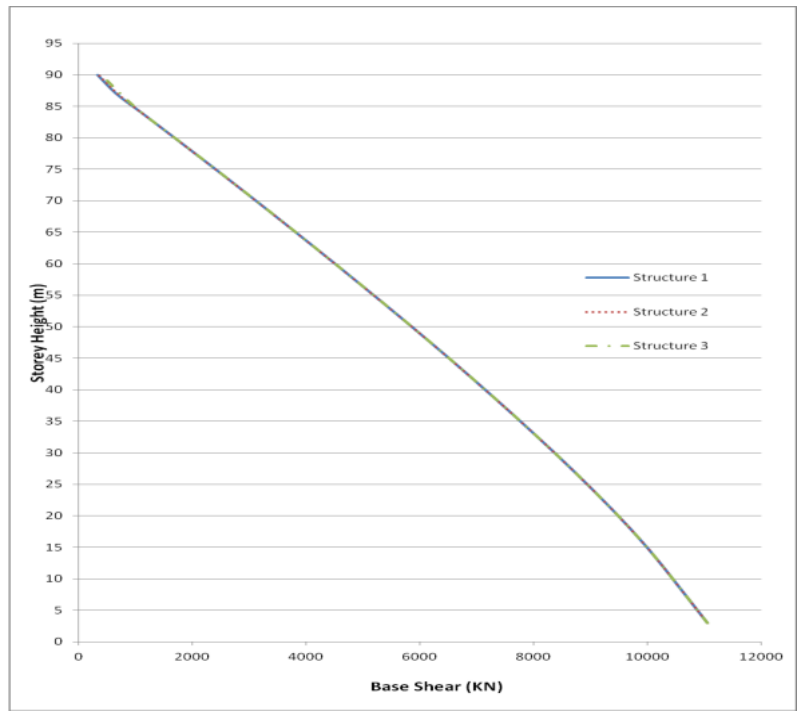

Fig.6 Storey wise distribution of base shear (in $\mathrm{kN}$ ) for all structures in Y-direction

Similarly from the fig 6 the base shear values are same for the three structures in Y-direction. At top storey the base shear is slightly more in Structure 3 compared to structure 2 and 1 in both $\mathrm{X}$ and $\mathrm{Y}$ direction. 


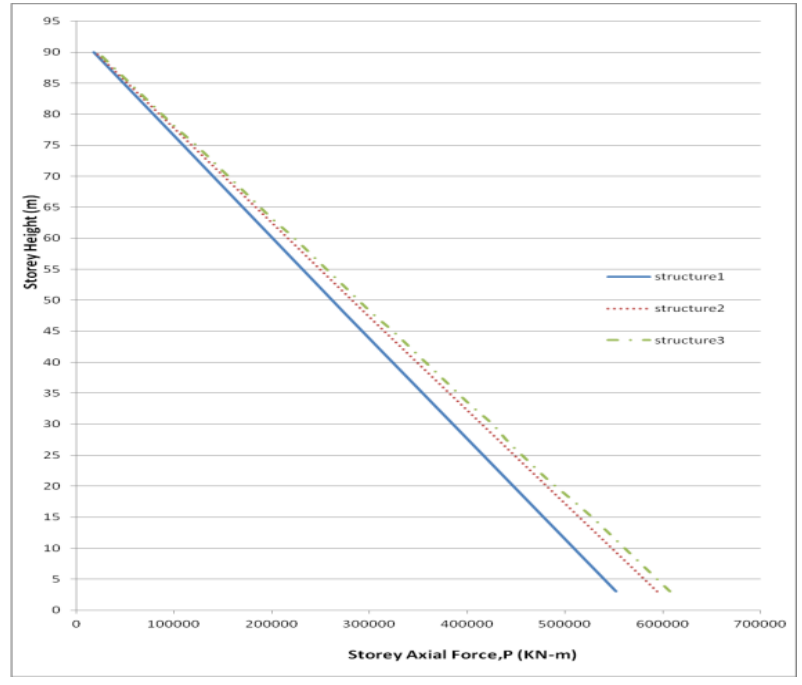

Fig.7 Storey Axial forces, $\mathrm{P}$ (in $\mathrm{kN}$ ) for all structures

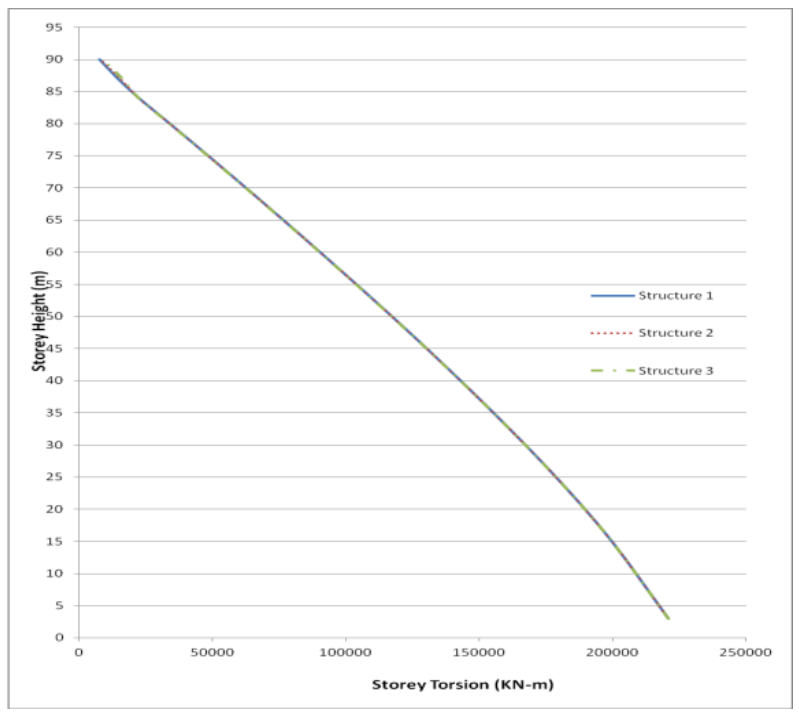

Fig. 8 Storey Torsion, $\mathrm{T}$ (in $\mathrm{kN}$ ) for all structures

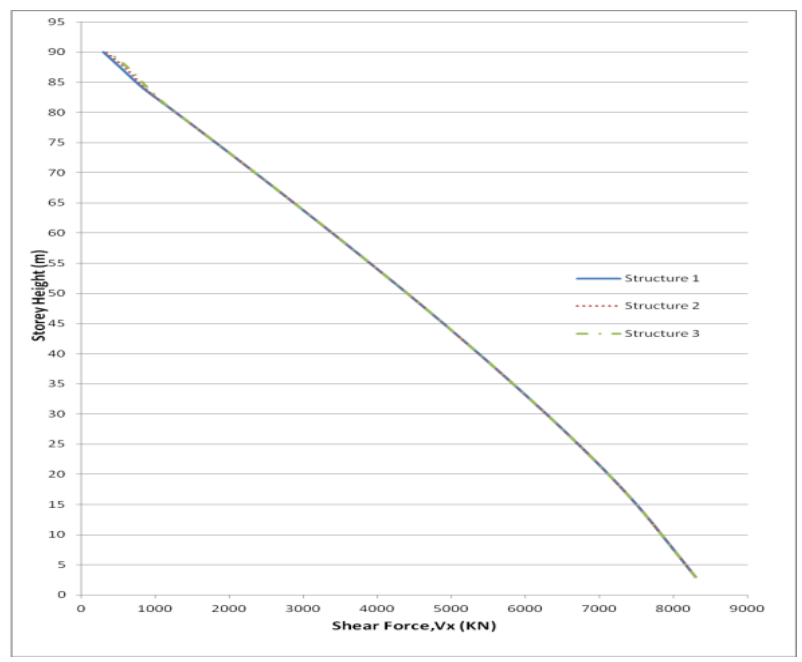

Fig.9 Storey Shear force, Vx (in $\mathrm{kN}$ ) for all structures

A graph is plotted taking storey axial force $(\mathrm{kN})$ on $\mathrm{X}$ axis and storey height $(\mathrm{m})$ on $\mathrm{Y}$ axis. From the fig 7 it is observed that the structure 3 is having more storey axial force compared to structure 1 and structure 2 . It is seen that as the stiffness of the structure is increased the axial force is also increased. The structure 3 is having more stiffness compared to structure 1 and 2 hence the structure 3 is having more axial force compared to other structures

A graph is plotted taking storey torsion $(\mathrm{kN}-\mathrm{m})$ on $\mathrm{X}$ axis and storey height $(\mathrm{m})$ on $\mathrm{Y}$ axis. From the fig 8 it is observed that all three structures are having same torsion values.

A graph is plotted taking storey shear $(\mathrm{kN})$ on $\mathrm{X}$ axis and storey height $(\mathrm{m})$ on $\mathrm{Y}$ axis. From the fig 9 it is observed that all the three structures are having the same shear force value in X-direction.

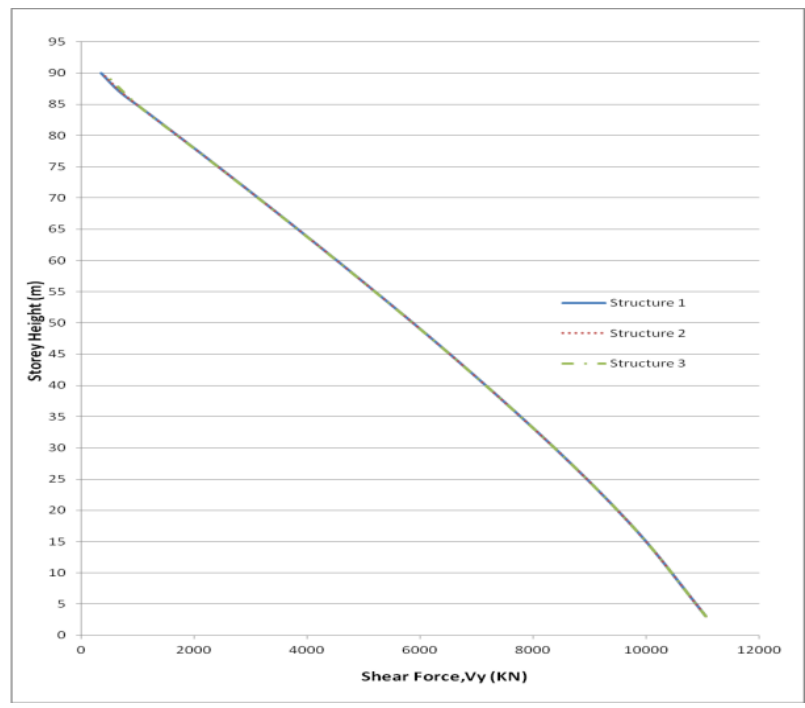

Fig.10 Storey Shear force, Vy (in $\mathrm{kN}$ ) for all structures

Similarly from the fig 10 the shear force values are same for the three structures in Y-direction. At top storey the shear force value of structure 3 is slightly more than other structures both in $\mathrm{X}$ and $\mathrm{Y}$ direction

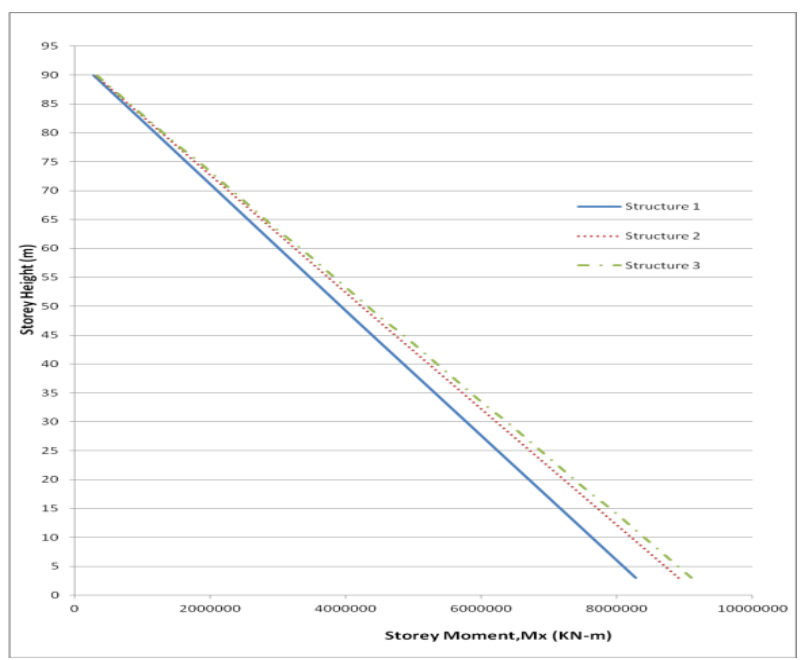

Fig.11 Storey Moment, Mx (in kN-m) for all structures

A graph is plotted taking storey moment $\mathrm{Mx}(\mathrm{kN}-\mathrm{m})$ on $\mathrm{X}$ axis and storey height $(\mathrm{m})$ on $\mathrm{Y}$ axis. From the fig 11, it is 
observed that the structure 3 is having more moment compared to other structures. The maximum moment in structure 1 is $7.03 \%$ and $8.98 \%$ less compare to Structure 2 and Structure 3 respectively.

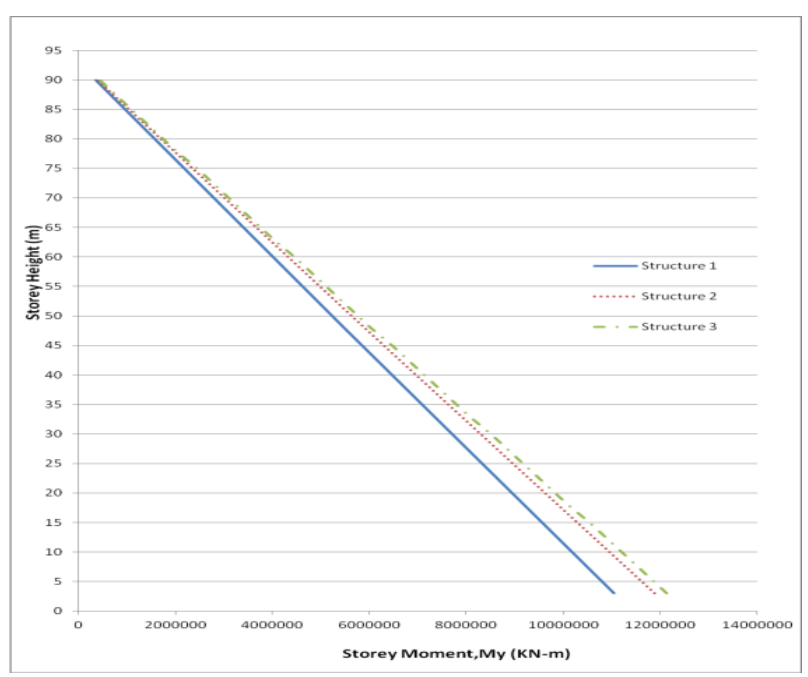

Fig.12 Storey Moment, My (in kN-m) for all structures

A graph is plotted taking storey moment My $(\mathrm{kN}-\mathrm{m})$ on $\mathrm{X}$ axis and storey height $(\mathrm{m})$ on $\mathrm{Y}$ axis. From the fig 12 it is observed that the structure 3 is having more moment compared to other structures. The maximum moment in structure 1 is $7.03 \%$ and $8.98 \%$ less compare to Structure 2 and Structure 3 respectively

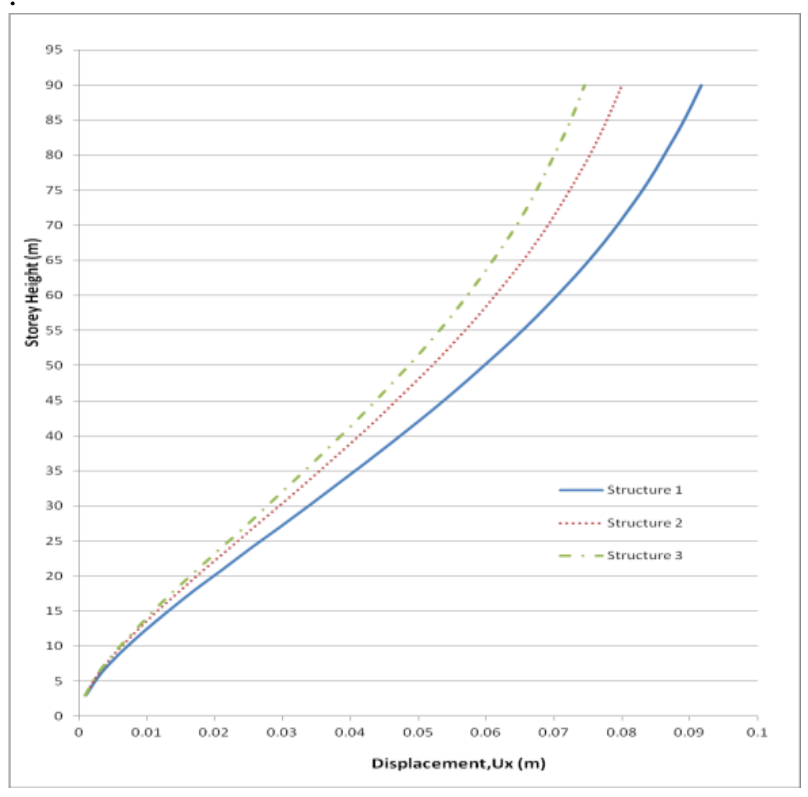

Fig.13 Diaphragm CM displacement, Ux (in $\mathrm{m}$ ) for all structures

A graph is plotted taking diaphragm displacement Ux (m) on $\mathrm{X}$ axis and storey height $(\mathrm{m})$ on $\mathrm{Y}$ axis. From the fig 13 it is observed that the structure 3 is having less displacement compared to other structures. The maximum displacement in structure 1 is $12.75 \%$ and $18.75 \%$ more compare to Structure 2 and Structure 3 respectively. As the stiffness is increased in structure 3 the displacement is reduced

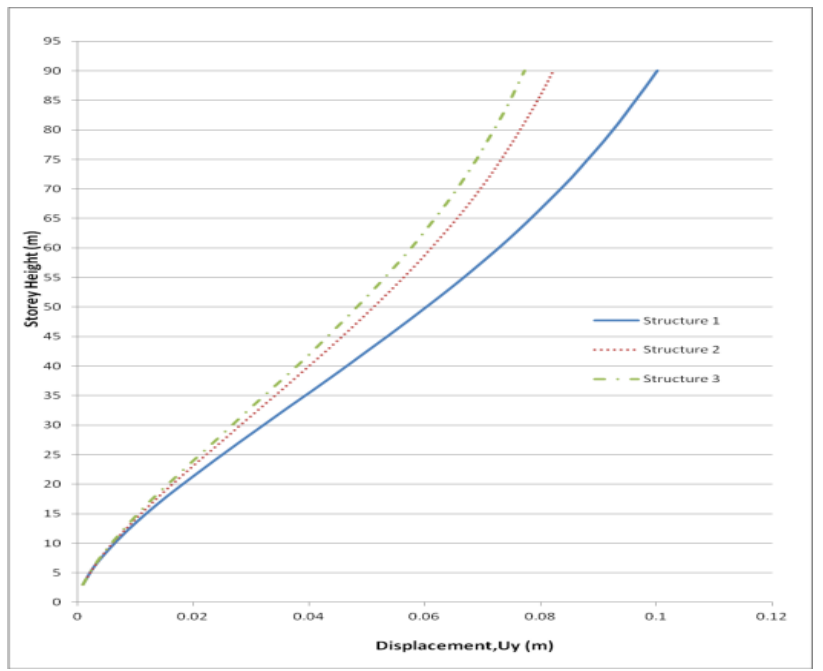

Fig.14 Diaphragm CM displacement, Uy (in $\mathrm{m}$ ) for all structures

A graph is plotted taking diaphragm displacement $\mathrm{Uy}(\mathrm{m})$ on $\mathrm{X}$ axis and storey height $(\mathrm{m})$ on $\mathrm{Y}$ axis. From the fig 14 it is observed that the structure 3 is having less displacement compared to other structures. It is seen that as the stiffness is increased the displacement in structure is reduced. The maximum displacement in structure 1 is $17.96 \%$ and $22.85 \%$ more compare to Structure 2 and Structure 3 respect

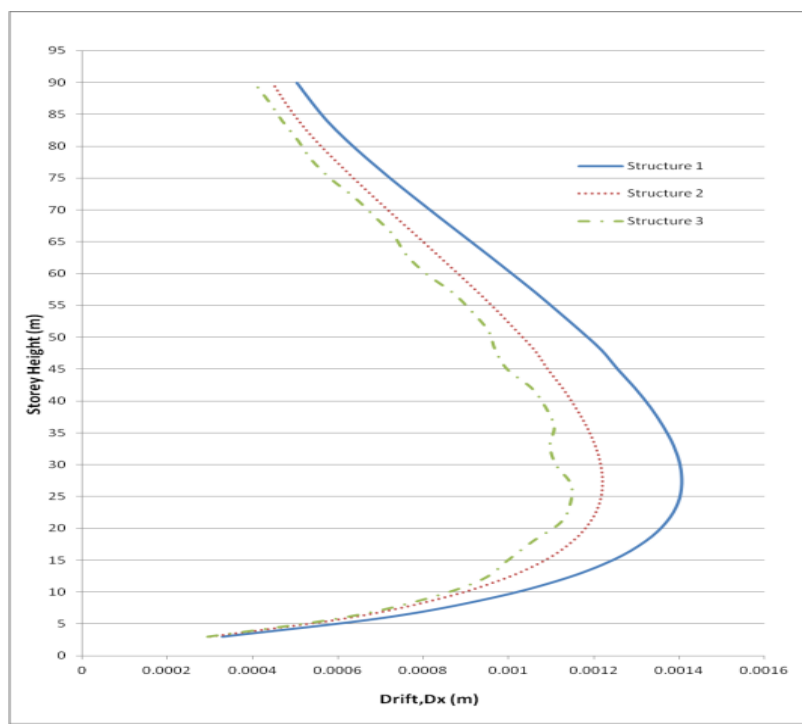

Fig.15 Storey Drift, Dx (in m) for all structures

A graph is plotted taking storey drift Dx (m) on X axis and storey height $(\mathrm{m})$ on $\mathrm{Y}$ axis. From the fig 15 it is observed that the structure 1 is having more drift compared to other structures. The maximum drift in structure 1 is $13.29 \%$ and $18.55 \%$ more compare to Structure 2 and Structure 3 respectively. It is observed that as the stiffness of structure 3 is more compared to other structures the drift is reduced in structure 3 . 


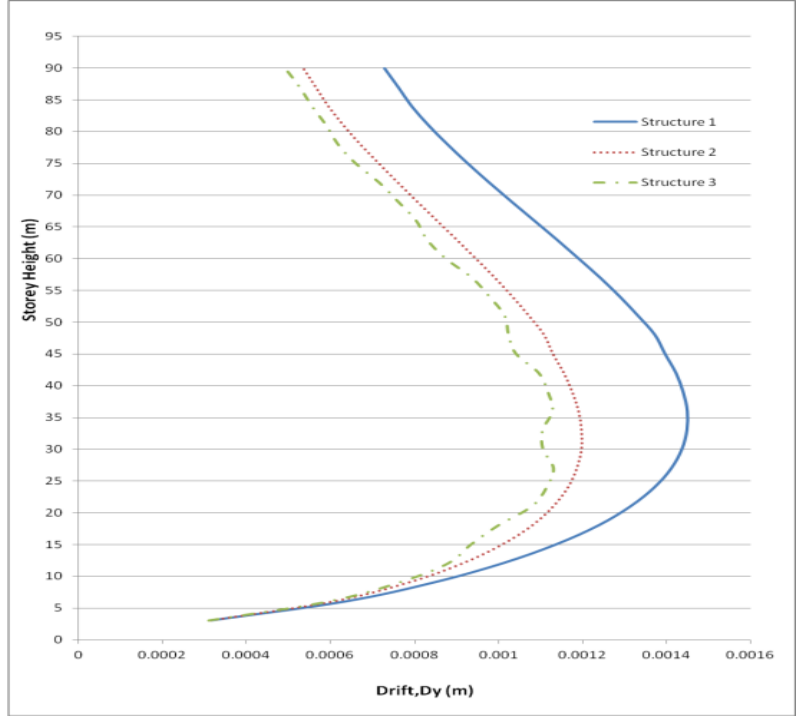

Fig.16 Storey Drift, Dy (in m) for all structures

A graph is plotted taking storey drift Dy (m) on $\mathrm{X}$ axis and storey height $(\mathrm{m})$ on $\mathrm{Y}$ axis. From the fig 16 it is observed that the structure 3 is having less drift compared to other structures. The maximum drift in structure 1 is $17.33 \%$ and $21.89 \%$ more compare to Structure 2 and Structure 3 respectively.

It is observed that as the stiffness of structure 3 is more compared to other structures the drift is reduced in structure

\section{Discussion of Results}

From the Analysis and Experiments the Results are as follows:

There are no abrupt changes in Column Size from one Storey to another and no significant Geometrical irregularities. Thus weak and soft storey does not exist in design.

\subsection{Based on max. Centre of mass (CM) displacement and} storey drifts considerations: (In $X \& Y$ Directions)

- In X- Direction, the Maximum CM Displacement in Structure 1: Flat Slab $200 \mathrm{~mm}$ with Drop is $91.7 \mathrm{~mm}$ which is $12.75 \%$ and $18.75 \%$ more compare to Structure 2 and Structure 3 respectively.

- In Y- Direction, the Maximum CM Displacement in Structure 1: Flat Slab $200 \mathrm{~mm}$ with Drop is 100.2 $\mathrm{mm}$ which is $17.96 \%$ and $22.85 \%$ more compare to Structure 2 and Structure 3 respectively.

- In X- Direction, the Maximum Storey Drift in Structure 1: Flat Slab $200 \mathrm{~mm}$ with Drop is $1.407 \mathrm{~mm}$ which is $13.29 \%$ and $18.55 \%$ more compare to Structure 2 and Structure 3 respectively.

- In Y- Direction, the Maximum Storey Drift in Structure 1: Flat Slab $200 \mathrm{~mm}$ with Drop is $1.448 \mathrm{~mm}$ which is $17.33 \%$ and $21.89 \%$ more compare to Structure 2 and Structure 3 respectively.

- As per IS 1893 (Part1):2002 clause 7.11.1 limiting storey drift is 0.004 times storey height. i.e. 0.004 $\mathrm{x} 3.0 \mathrm{~m}=0.012 \mathrm{~m}$ or $12 \mathrm{~mm}$. The Maximum Storey Drift for all the structures in both directions for the Load cases is less than the limiting value.

\subsection{Maximum Axial Forces Considerations}

- In Structure 1: Flat Slab $200 \mathrm{~mm}$ with Drop is $552387 \quad \mathrm{kN}$ which is $7.03 \%$ and $8.98 \%$ less compare to Structure 2 and Structure 3 respectively.

- In Structure 1: Flat Slab $200 \mathrm{~mm}$ with Drop for C7 is $-18645 \mathrm{kN}$ which is $1.13 \%$ and $2.69 \%$ less compare to Structure 2 and Structure 3 and for C20 is -19789 KN which is $1 \%$ and $2.25 \%$ less compare to Structure 2 and Structure 3 respectively.

\subsection{Maximum Shear Forces Vx \& Vy Considerations}

- In X-direction in Structure 1: Flat Slab $200 \mathrm{~mm}$ with Drop is $8293 \mathrm{kN}$ which is same for Structure 2 and Structure 3 respectively.

- In Y-direction in Structure 1: Flat Slab $200 \mathrm{~mm}$ with Drop is $11057 \mathrm{kN}$ which is same for Structure 2 and Structure 3 respectively.

- The Maximum column Shear Forces :In X-direction in Structure 1: Flat Slab $200 \mathrm{~mm}$ with Drop for C7 is $-108 \mathrm{kN}$ which is $28.9 \%$ and $43.75 \%$ less compare to Structure 2 and Structure 3 and for C20 is $96 \mathrm{KN}$ which is $31.9 \%$ and $44.82 \%$ less compare to Structure 2 and Structure 3 respectively.

- In Y-direction in Structure 1: Flat Slab $200 \mathrm{~mm}$ with Drop for C7 is $-214 \mathrm{kN}$ which is $21.6 \%$ and $35.92 \%$ less compare to Structure 2 and Structure 3 and for $\mathrm{C} 20$ is $138 \mathrm{KN}$ which is $38.9 \%$ and $48.88 \%$ less compare to Structure 2 and Structure 3 respectively.

\subsection{Maximum Torsion Considerations}

- In Structure 1: Flat Slab $200 \mathrm{~mm}$ with Drop is $221027 \mathrm{kN}-\mathrm{m}$ which is $0.01 \%$ and $0.01 \%$ less compare to Structure 2 and Structure 3 respectively.

- In Structure 1: Flat Slab $200 \mathrm{~mm}$ with Drop for C7 is $-2.4 \mathrm{kN}-\mathrm{m}$ which is $11.11 \%$ and $11.11 \%$ less compare to Structure 2 and Structure 3 and for C20 is $2.4 \mathrm{KN}$ $\mathrm{m}$ which is $11.11 \%$ and $11.11 \%$ less compare to Structure 2 and Structure 3 respectively.

\subsection{Maximum Moments, Mx\& My Considerations}

- In X-direction in Structure 1: Flat Slab $200 \mathrm{~mm}$ with Drop is $8285759 \mathrm{kN}$ which is $7.03 \%$ and $8.98 \%$ less compare to Structure 2 and Structure 3 respectively.

- In Y-direction in Structure 1: Flat Slab $200 \mathrm{~mm}$ with Drop is $-11047705 \mathrm{kN}$ which is $7.03 \%$ and $8.98 \%$ less compare to Structure 2 and Structure 3 respectively.

- The Maximum column Moment in X-direction in Structure 1: Flat Slab $200 \mathrm{~mm}$ with Drop for C7 is $386 \mathrm{kN}$ which is $11.46 \%$ and $36.09 \%$ less compare to Structure 2 and Structure 3 and for C20 is $309 \mathrm{KN}$ which is $14.40 \%$ and $36.55 \%$ less compare to Structure 2 and Structure 3 respectively. 
- In Y-direction in Structure 1: Flat Slab $200 \mathrm{~mm}$ with Drop for C7 is $-308 \mathrm{kN}$ which is $3.89 \%$ more compare to Structure 2 and $10.98 \%$ less compare to Structure 3 and for $\mathrm{C} 20$ is $307 \mathrm{KN}$ which is $3.58 \%$ more compare to Structure 2 and $7.53 \%$ less compare to Structure 3 respectively.

\subsection{Maximum Column Point Displacements, $U x \& U y$ Considerations}

The limiting displacement is $\mathrm{H} / 500$ i.e. $=180 \mathrm{~mm}$. The maximum displacements of all the structures are within the limit as per Table No 4.13 and 4.14 .

As per Clause 7.8.4.2 of IS 1893 ( Part I):2000, The number of modes to be used in the analysis should be such that the sum total of modal masses of all modes considered is at least 90 percent of the total seismic mass and missing mass correction beyond $33 \mathrm{~Hz}$ are to be considered.

As per Table No 4.17 the total sum of modal masses of all modes considered is greater than 90 percent of the total seismic mass for all Structures

\section{Conclusions}

In the dissertation work, entitled Effect of Increased Stiffness of Diaphragm on Lateral Loads analytical study is carried out on a building with increased stiffness of diaphragm. The 3D analysis of building is carried out for Seismic Zone III and Terrain Category III. The main objective of the study is to reduce the lateral forces by increasing the stiffness. The study has been carried out to analyze the following cases.

Structure 1: Flat Slab 200mm with Drop

Structure 2: Flat Slab 250mm without Drop

Structure 3: Increased stiffness of diaphragm 300mm at regular intervals.

All the above building models are generated using the finite element software ETABS v9.6 and are analysed using response spectrum method (linear dynamic method). Based on the analysis results following conclusions are drawn

1. The CM displacement in structure 1 is higher than structure 2 and structure 3 because of less lateral resistance and stiffness.

2. By increasing the stiffness of diaphragm the $\mathrm{CM}$ displacement is reduced in structure 3 compared to structure 2 and structure 1 .
3. The storey drift in structure 1 is higher than structure 2 and structure 3 because of less stiffness.

4. The study indicates that Structure 2: Flat Slab $250 \mathrm{~mm}$ without Drop significantly improve the behaviour than Structure 1: (Flat Slab 200mm with Drop) due to increased stiffness of diaphragm.

5. There is further improvement in performance of the structure with increased stiffness of diaphragm at regular intervals. Hence Structure 3: (Increased stiffness of diaphragm $300 \mathrm{~mm}$ at regular intervals) shows better performance.

\section{References}

Bureau Of Indian Standards IS: 875 (Part 2) - 1987 (Second Revision), New Delhi, India. Indian Standard Code of Practice for Design Load (other than earthquake) For Buildings and Structures, Part -2 Live Loads,

Indian Standard Code of Practice for Design Load (other than earthquake) For Buildings and Structures, Part - 3 Wind Loads, IS: 875 (Part 3) - 1987 (Second Revision), Bureau Of Indian Standards, New Delhi, India.

Indian Standard Criteria For Earthquake Resistant Design Of Structures IS: 1893 (Part 1) 2002, Part 1 General Provisions and Buildings (Fifth Revision), Bureau Of Indian Standards, New Delhi, India.

Indian Standard Criteria For Earthquake Resistant Design Of Structures IS: 1893 (Part 1) 2002, Part 1 General Provisions and Buildings (Fifth Revision), Bureau Of Indian Standards, New Delhi, India.

IS: 456 - 2000 - Code of practice for plain and Rein forced concrete (Fourth Revision), Bureau of Indian Standards, New Delhi, India.

Taranath.B.S. (2001) Steel, Concrete and Composite Design Of Tall Buildings, Second Edition, McGraw - Hill.

Laporan Akhir, November 2006, The Effects of Diaphragm Components in resisting Lateral Stability of precast Concrete Frames.

Dong- Guen Lee, et-al. 2004 Use of Super Elements for An Efficient Analysis of High-rise Building Structures for $C T B U H$, Seoul, Korea.

Young S.Cho, 'et-al.' 2004 A study of Flat Plate Slab - Column connections with Shear Plate in tall concrete building using Experimental and Numerical Analysis - for CTBUH, Seoul, Korea

P. Jayachandran, May 2009, design of Tall Buildings Preliminary Design and Optimization National Workshop on High-rise and Tall Buildings, University of Hyderabad, Hyderabad, India.

K. Galal and H. El-Sokkary 2008 Advancement in Modeling of RC Shear Walls, the $14^{\text {th }}$ World Conference on Earthquake Engineering, Beijing, China.

ETABS Software, Documentation and Tutorials, C.S. Inc. 